\title{
Effect of Sustained Load on the Passive Film of Carbon Steel Embedded in Concrete
}

\author{
Sen Pang ${ }^{1, *}$, Bo Diao ${ }^{1,2}$, Yinghua Ye $e^{1}$ \\ ${ }^{1}$ School of Transportation Science and Engineering, Beihang University, Beijing 100191, China.; \\ pang.sn@buaa.edu.cn(S.Pang);diaobo@buaa.edu.cn(B.Diao);yhye@buaa.edu.cn(Y.H.Ye); \\ ${ }^{2}$ State Laboratory of Subtropical Building Science, South China University of Technology, \\ Guangzhou 510640, China. \\ *E-mail: pang.sn@buaa.edu.cn
}

doi: $10.20964 / 2017.06 .25$

Received: 6 March 2017 / Accepted: 11 April 2017 / Published: 12 May 2017

Reinforced concrete structures experience different kinds of load, which may influence the passive behaviour of steel. For the purpose of simulating in-service condition, the steel sample for electrochemical measurement was embedded in concrete in this study. The effects of sustained load level and duration on the passive behaviour of carbon steel were studied via electrochemical impedance spectroscopy. The protective effect of passive film decreased as the load level increased. A re-passivation kinetics was detected during sustained loading. The degree of re-passivation decreased when the load level increased. A peak of re-passivation was observed after the load was sustained for 24h. Electrochemical measurement applied on steel embedded in concrete offers the possibility of nondestructive testing in reinforced concrete structures.

Keywords: Steel reinforced concrete; EIS; Passive films; Re-passivation; Effects of strain;

\section{$\underline{\text { FULL TEXT }}$}

(C) 2017 The Authors. Published by ESG (www.electrochemsci.org). This article is an open access article distributed under the terms and conditions of the Creative Commons Attribution license (http://creativecommons.org/licenses/by/4.0/). 